\title{
Phase II study of NGR-hTNF in combination with doxorubicin in relapsed ovarian cancer patients
}

\section{Lorusso', G Scambia', G Amadio', A di Legge', A Pietragalla', R De Vincenzo', V Masciullo', M Di Stefano', G Mangili', G Citterio ${ }^{3}$, M Mantori ${ }^{4}$, A Lambiase ${ }^{4}$ and C Bordignon*,4,5}

'Department of Gynecologic Oncology, Catholic University of Rome, Rome, Italy; '2Department of Gynecologic Oncology, San Raffaele Institute, Milan, Italy; ${ }^{3}$ Department of Oncology, San Raffaele Institute, Milan, Italy; ${ }^{4}$ MolMed, Milan, Italy; ${ }^{5}$ Università Vita-Salute San Raffaele, Via Olgettina, 60, Milan 20/32, Italy

BACKGROUND: The NGR-hTNF (asparagine-glycine-arginine-human tumour necrosis factor) is able to promote antitumour immune responses and to improve the intratumoural doxorubicin uptake by selectively damaging tumour blood vessels.

METHODS: Patients progressing after $\geqslant 1$ platinum/taxane-based regimen received NGR-hTNF $0.8 \mu \mathrm{gm}^{-2}$ and doxorubicin $60 \mathrm{mg} \mathrm{m}^{-2}$ every 3 weeks. Primary endpoint was a Response Evaluation Criteria in Solid Tumors-defined response rate with a target of more than 6 out of 37 responding patients.

RESULTS: A total of 37 patients with platinum-free interval lower than 6 months $(\mathrm{PFI}<6 ; n=25)$, or between 6 and 12 months $(\mathrm{PFI}=6-12 ; n=12)$ were enrolled. Median baseline peripheral blood lymphocyte count (PBLC) was 1.6 per $\mathrm{ml}$ (interquartile range, I.2-2. I). In all, 18 patients (49\%) received more than 6 cycles. Febrile neutropaenia was registered in one patient (3\%). Among 35 assessable patients, 8 (23\%; 95\% Cl 12-39\%) had partial response (2 with PFI<6; 6 with PFI = 6-I2) and I5 (43\%) had stable disease $(\mathrm{I} 0$ with $\mathrm{PFI}<6 ; 5$ with $\mathrm{PFI}=6-12)$. Median progression-free survival (PFS) was 5.0 months for all patients, 3.8 months for patients with $\mathrm{PFI}<6$, and 7.8 months for patients with $\mathrm{PFI}=6-12$. Median overall survival (OS) was 17.0 months. Patients with baseline PBLC higher than the first quartile had improved PFS $(P=0.0 \mathrm{I})$ and $O S(P=0.00 \mathrm{I})$.

CONCLUSION: Tolerability and activity of this combination warrant further randomised testing in patients with PFI $<6$. The role of PBLC as a blood-based biomarker deserves further investigation.

British Journal of Cancer (2012) 107, 37-42. doi:10.1038/bjc.2012.233 www.bjcancer.com

Published online 29 May 2012

(C) 2012 Cancer Research UK

Keywords: NGR-hTNF; vascular targeting agent; doxorubicin; ovarian cancer

Ovarian cancer is the sixth most common cancer in women in the United States and Europe (Jemal et al, 2011). Most patients present with advanced stage disease and though the majority of them experience remission after surgery and a frontline platinum/ taxane-based regimen, the relapse rate is $80 \%$ (Bookman et al, 2009). Historically, the efficacy of chemotherapy retreatment in relapsed ovarian cancer has been correlated with prior platinum sensitivity, namely with the platinum-free interval (PFI; Cannistra, 2004). Although a PFI greater than 6 months predicts platinum sensitivity, within this group, patients with an interval greater than 12 months are considered fully sensitive and commonly retreated with platinum-containing regimens, whereas patients with a PFI between 6 and 12 months are believed to have partially platinumsensitive relapse. In this patient subset, both preclinical and clinical data suggest that the artificial prolongation of PFI with a nonplatinum-based therapy may be beneficial in reversing platinum resistance (Monk et al, 2010; Poveda et al, 2011). Conversely, patients who progress while receiving firstline therapy or within 6 months from its completion are considered to have refractory/resistant relapse, which is typically retreated with a monotherapy of nonplatinum agents, such as pegylated liposomal doxorubicin (PLD), gemcitabine, or topotecan, with a

*Correspondence: Dr C Bordignon; E-mail: claudio.bordignon@hsr.it Received I March 20 12; revised 26 April 2012; accepted 30 April 20 12; published online 29 May 2012 disappointing median survival of about 10 months from the time of recurrence (Rose et al, 2010). In view of the dismal prognosis, new treatment options are therefore required to improve outcome in recurrent ovarian cancer, especially in platinum-refractory/ resistant relapse.

Tumour necrosis factor (TNF) has shown a powerful preclinical activity that is primarily mediated by inducing apoptosis of cancer endothelial cells (Carswell et al, 1975) and promoting antitumour immune responses (Scheurich et al, 1987). However, the earlystage clinical trials were hampered by severe toxicities when TNF was given systemically, whereas the locoregional delivery by isolated perfusion of high-dose TNF plus chemotherapy has been associated with increased response rates in melanoma, sarcoma, and liver cancer (Lejeune et al, 2006).

To exploit a ligand-directed approach, the NGR-hTNF (asparagineglycine-arginine-human TNF) was prepared by fusing the $\mathrm{N}$ terminus of TNF with the C terminus of the peptide NGR, which is able to selectively recognise a CD13 isoform overexpressed on tumour endothelium (Curnis et al, 2000). Remarkably, CD13 is not (or barely) expressed in normal blood vessels, and its crucial role into the pathological development of new vessels from pre-existing vessels (i.e., angiogenesis) has been recently confirmed in a CD13null model (Rangel et al, 2007). In preclinical models, NGR-hTNF induced antitumour effects 10 -fold higher than the untargeted TNF and displayed a biphasic dose-response curve, with activity shown even at very low doses. Interestingly, tumour regressions induced 
by low doses of NGR-hTNF were accompanied by protective immunity, implying that the targeted delivery of TNF to tumour may also improve its immunotherapeutic properties (Curnis et al, 2000).

Besides the ability of inducing apoptosis of tumour endothelial cells, NGR-hTNF also decreases the interstitial fluid pressure by altering the integrity of endothelial cell barrier, a process pivotal in facilitating the intratumoural chemotherapy uptake. The mechanism by which NGR-hTNF increases endothelial permeability and drug penetration in tumour relies on rapid disassembly of vascular endothelial-cadherin-dependent adherence junctions and formation of intercellular gaps that are followed by vascular damage at later time points (Dondossola et al, 2011). Consistently with a selective activity, even low doses of NGR-hTNF exerted synergistic effects in vivo when combined with various chemotherapeutic drugs, especially doxorubicin, without increasing the in vitro cytotoxicity of chemotherapy, likely because of indirect effects on host cells rather than direct effects on tumour cells (Curnis et al, 2002). Indeed, synergism was sequence- and time-dependent, being observed when NGR-hTNF was given $2 \mathrm{~h}$ before chemotherapy dosing, and not with shorter or longer time intervals (Sacchi et al, 2006). Notably, the synergism with doxorubicin has been shown in immunocompetent mice, but not in athymic nude mice lacking functionally mature T lymphocytes (Sacchi et al, 2004).

The rationale for testing an antivascular approach in ovarian cancer is highly appealing. Both preclinical and clinical data have confirmed the key role of angiogenesis in ovarian cancer pathophysiology (Kumaran et al, 2009). Moreover, CD13 is highly expressed in ovarian cancer, and CD13-overexpressing tumours resistant to cisplatin in vivo do not show reduced sensitivity in vitro, thus suggesting that inadequate drug delivery to tumour rather than CD13-induced resistance is involved (van Hensbergen et al, 2004). Interestingly, the highest doxorubicin sensitivity in vivo is observed in tumour microenvironments with increased vascular permeability (Nakasone et al, 2012).

Two single-agent phase I trials established the maximum tolerated dose of NGR-hTNF at $45 \mu \mathrm{g} \mathrm{m}^{-2}$ (van Laarhoven et al, 2010) and the optimal biological dose at $0.8 \mu \mathrm{g} \mathrm{m}^{-2}$ (Gregorc et al, 2010a), with both doses delivered every 3 weeks. Given the equivalent activity and better tolerability, the low dose was used for further clinical testing. Two single-agent phase II trials documented the clinical activity of NGR-hTNF $0.8 \mu \mathrm{g} \mathrm{m}^{-2}$ in liver cancer (Santoro et al, 2010) and mesothelioma (Gregorc et al, 2010b) patients who were refractory/resistant to standard treatments. A phase I combination trial selected NGR-hTNF $0.8 \mu \mathrm{g} \mathrm{m}^{-2}$ plus standard doxorubicin doses (60 or $75 \mathrm{mg} \mathrm{m}^{-2}$ ) for phase II testing, with a promising disease control experienced by $73 \%$ of patients for a median time of 5.5 months, without apparent increase of doxorubicin-related toxicity (Gregorc et al, 2009).

The present phase II trial was undertaken to evaluate activity and safety of the combination of NGR-hTNF and doxorubicin in advanced ovarian cancer patients relapsing after platinum/taxanebased chemotherapy. Doxorubicin was used in this trial because of lack of preclinical and phase I clinical data with PLD.

\section{METHODS}

\section{Patient eligibility}

Patients older than age 18 years, with advanced ovarian cancer previously treated with at least one platinum-based regimen (either cisplatin or carboplatin plus paclitaxel) and with radiologic evidence of tumour progression on treatment or within 6 months of completing therapy (platinum-refractory/resistant relapse), or between 6 to 12 months (partially platinum-sensitive relapse), were eligible. Patients were also required to have at least one unidimentionally measurable lesion by the Response Evaluation
Criteria in Solid Tumors (RECIST) version 1.1, an Eastern Cooperative Oncology Group performance status (ECOG PS) of 0 or 1, and adequate system/organ function. Patients with significant cardiovascular disease, including a left ventricular ejection fraction (LVEF) less than 55\%, completing radiation therapy or chemotherapy within 4 weeks, or having surgery within 2 weeks before treatment start were excluded. Written informed consent was received by all patients. Study protocol was approved by the Institutional Ethics Committees and was registered in www.ClinicalTrials.gov, number NCT00484432.

\section{Treatment plan}

Primary objective of this multicentre, single-arm phase II trial was to assess the antitumour activity of the NGR-hTNF and doxorubicin combination in terms of objective response rate, defined as the proportion of patients with complete response (CR) or partial response (PR) according to the RECIST criteria. Radiological studies were done at baseline and every other cycle (6 weeks) by computed tomography or magnetic resonance imaging. Investigator-determined responses (CR or PR) had to be confirmed at least 4 weeks later. Disease control rate was defined as the percentage of patients who had a best-response rating of $\mathrm{CR}$ or PR, or stable disease (SD). Secondary efficacy variables included progression-free survival (PFS) and overall survival (OS). Here, PFS was defined on the basis of the first evidence of either radiological progression or death due to any cause, and OS was defined on the basis of the date of death due to any cause. For patients without documented progression or death at the time of analysis, PFS was censored at the last date of tumour evaluation and OS at the last date of follow-up. Additional secondary objectives included assessment of CA-125 response every other cycle, using the Gynaecological Cancer Intergroup (GCIG) criteria (Rustin, 2003), and evaluation of toxicity on an ongoing basis throughout the study using the Common Terminology Criteria for Adverse Events, version 3.0. Physical examinations and laboratory tests (complete blood counts and serum chemistries) were done at baseline and before each cycle (3 weeks).

The NGR-hTNF $\left(0.8 \mu \mathrm{g} \mathrm{m}^{-2}\right)$ was given intravenously as 1 -h infusion, followed by doxorubicin $60 \mathrm{mg} \mathrm{m}^{-2}$ as 15 -min infusion, which was started $2 \mathrm{~h}$ after the beginning of the NGR-hTNF dosing. Maximum cumulative dose of doxorubicin was capped at $550 \mathrm{mg} \mathrm{m}^{-2}$, whereas NGR-hTNF was continued until progression, unacceptable toxicity, or patient request. For retreatment on next cycle, all toxicities should be recovered to grade 1 or less. For patients unable to meet retreatment criteria, a 1-to-3 week delay for both drugs was allowed. No formal dose reduction for NGRhTNF was planned. Premedication with paracetamol was recommended for next cycles if chills had occurred on prior infusions. Doxorubicin dose was reduced by $25 \%$ for febrile neutropaenia or prolonged grade 4 neutropaenia, and by $50 \%$ in case of serum bilirubin levels between 1.2 to $3.0 \mathrm{mg} \mathrm{dl}^{-1}$. Doxorubicin was permanently discontinued in case of creatinine clearance $<60 \mathrm{ml} \mathrm{min}^{-1}$, grade $\geqslant 3$ neurotoxicity, New York Heart Association $\geqslant$ III congestive heart failure, and reduction of LVEF $\geqslant 20 \%$ from baseline or to $\leqslant 45 \%$ as absolute value.

\section{Statistical analysis}

Primary study endpoint was response rate as per the RECIST criteria. Sample size was calculated using a Simon two-stage optimal design, with an expected response rate of $10 \%$ for a singleagent doxorubicin (Mutch et al, 2007; Ferrandina et al, 2008) and an increase up to $30 \%$ with the addition of NGR-hTNF. Accordingly, 17 patients were to be accrued in the first study stage. If at least 2 responses were registered, a total of 37 patients should be recruited, and study treatment could be considered worthy of further testing if 6 or more responses were documented. 
This two-stage design yielded a power of $90 \%$ to discriminate between true response rate of 10 and $30 \%$. Type I alpha error was set at 5\%. Maximal changes in tumour target lesions from baseline were also plotted as a waterfall plot, and changes over treatment in the sum of longest diameters of target lesions as a spider plot. Both PFS and OS were estimated by the Kaplan-Meier method with an intent-to-treat analysis. An exploratory, univariate Cox model was fit to examine the impact of baseline characteristics of outcome. Tested variables included age (as a continuous variable), ECOG PS (0 vs 1), PFI (lower than 6 months vs 6 to 12 months), and peripheral blood lymphocyte count (PBLC) at baseline (equal or higher $v s$ lower than the 25 th percentile distribution value). The log-rank test was used for comparisons of time-to-event data between subgroups of patients. Subset analyses were exploratory in nature. All analyses were performed with SPSS 13.0 (SPSS Inc., Chicago, IL, USA) and GraphPad (GraphPad Software, Inc., San Diego, CA, USA).

\section{RESULTS}

\section{Patient characteristics}

A total of 37 patients with radiologically documented tumour progression after the last treatment regimen were enrolled. The median PFI was 4.6 months (95\% CI 3.1-5.7). All patients had previously received both paclitaxel and a platinum compound. Baseline patient characteristics are listed in Table 1.

\section{Toxicity}

Among all patients, 177 cycles (median 4, range 1-8) were delivered. Eighteen patients (49\%) received at least 6 cycles and

Table I Baseline patient characteristics

\begin{tabular}{|c|c|c|c|}
\hline Characteristics & $n=37$ & & $\%$ \\
\hline \multicolumn{4}{|l|}{ ECOG PS } \\
\hline 0 & 32 & & 86 \\
\hline 1 & 5 & & 14 \\
\hline \multicolumn{4}{|l|}{ Number of prior systemic regimens } \\
\hline I & 30 & & 81 \\
\hline 2 or more & 7 & & 19 \\
\hline \multicolumn{4}{|l|}{ PFI after last treatment } \\
\hline$<6$ months (refractory/resistant relapse) & 25 & & 68 \\
\hline 6-12 months (partially sensitive relapse) & 12 & & 32 \\
\hline \multicolumn{4}{|l|}{ Patient age (years) } \\
\hline Median & & 57 & \\
\hline Range & & $35-72$ & \\
\hline \multicolumn{4}{|l|}{ CA-I 25 levels $\left(U \mathrm{ml}^{-1}\right)$} \\
\hline Median & & 556 & \\
\hline Range & & $6-5687$ & \\
\hline \multicolumn{4}{|l|}{ Sum of longest tumour diameters (mm) } \\
\hline Median & & 90 & \\
\hline Range & & $11-269$ & \\
\hline \multicolumn{4}{|l|}{ PBLC (per ml) } \\
\hline Median & & 1.6 & \\
\hline Interquartile range & & $1.2-2.1$ & \\
\hline \multicolumn{4}{|l|}{ Neutrophil-to-lymphocyte ratio } \\
\hline Median & & 2 & \\
\hline Interquartile range & & $2-4$ & \\
\hline
\end{tabular}

Abbreviations: $\mathrm{ECOG}=$ Eastern Cooperative Oncology Group; PBLC = peripheral blood lymphocyte count; PFI = platinum-free interval; PS = performance status.
12 patients $(32 \%)$ received 8 courses. At the time of analysis, no patient was on treatment. Treatment discontinuations resulted from radiologic progression or symptomatic deterioration in 29 patients $(78 \%)$, patient request in 7 cases $(19 \%)$, and toxicity in 1 patient $(3 \%)$.

Treatment-emergent adverse events (AEs), irrespective of relationship to study drugs, are displayed in Table 2. Nonhaematologic grade 3 and 4 AEs were reported in $7(19 \%)$ and 2 patients (5\%), respectively. Two patients (5\%) had grade 1 cardiac AEs (tachycardia and diastolic dysfunction). Only a small minority ( 50 out of $556,9 \%$ ) of all AEs recorded were related to NGR-hTNF infusion, being mostly represented by transient, infusion-related grade 1 or 2 chills in 24 patients $(65 \%)$. Concerning the haematological toxicity, grade 3 and 4 neutropaenia were registered in $7(19 \%)$ and 16 patients $(43 \%)$, and grade 3 and 4 anaemia in $9(24 \%)$ and 1 patient $(3 \%)$, respectively. Only one patient $(3 \%)$ had febrile neutropaenia. All cycles were given at the planned dose, with the exception of 8 patients $(22 \%)$ who required dose reduction of doxorubicin.

\section{Efficacy}

After enrolment of the first 17 patients, $6 \mathrm{PR}$ were reported and the trial met its primary endpoint. After the second study stage $(n=35$ assessable patients), 8 PR (23\%; 95\% CI 12-39) and 15 SD (43\%; $95 \%$ CI 28-59) were registered, for an overall disease control rate of $66 \%$ (95\% CI 49-79). Among 23 patients assessable by the GCIG CA-125 criteria, there were 9 responses (39\%; 95\% CI 22-59; 4 PR and 5 SD by the RECIST criteria). Median CA-125 levels at baseline and after 2, 4, 6, and 8 cycles were 556, 283, 124, 120, and $99 \mathrm{U} \mathrm{ml}^{-1}$, respectively. Efficacy results are summarised in Table 3, and individual patient radiological responses are plotted in Figure 1. Median PFS was 5.0 months for the whole study population (Figure 2A), 8.2 months (range 5.0-12.0) for patients who achieved PR, and 4.9 months (range 2.4-26.0) for patients who experienced SD.

After a median follow-up of 14.6 months, the estimated 1-year OS rate was $65 \%$ (Figure 2B). Median survival time was 24.0

Table 2 Adverse events (worst grade in more than 5\% of patients) irrespective of relationship to study drugs $(n=37)$

\begin{tabular}{|c|c|c|c|c|c|c|}
\hline \multirow[b]{2}{*}{ Adverse event } & \multicolumn{2}{|c|}{ Any grade } & \multicolumn{2}{|c|}{ Grade 3} & \multicolumn{2}{|c|}{ Grade 4} \\
\hline & $n$ & $\%$ & $n$ & $\%$ & $n$ & $\%$ \\
\hline Asthenia & 33 & 89 & I & 3 & - & - \\
\hline Anaemia & 31 & 84 & 9 & 24 & 1 & 3 \\
\hline Leukopaenia & 31 & 84 & 17 & 46 & I & 3 \\
\hline Nausea & 30 & 81 & - & - & - & - \\
\hline Neutropaenia & 29 & 79 & 7 & 19 & 16 & 43 \\
\hline Vomiting & 25 & 67 & - & - & - & - \\
\hline Chills & 24 & 65 & - & - & - & - \\
\hline Constipation & 23 & 62 & - & - & - & - \\
\hline Stomatitis & 19 & 51 & I & 3 & - & - \\
\hline Paraesthesia & 15 & 41 & - & - & - & - \\
\hline Headache & 8 & 22 & - & - & - & - \\
\hline Platelet count increased & 8 & 22 & 2 & 5 & - & - \\
\hline Diarrhoea & 7 & 19 & - & - & - & - \\
\hline Platelet count decreased & 5 & 13 & 1 & 3 & - & - \\
\hline Alanine aminotransferase increased & 4 & || & l & 3 & - & - \\
\hline Pyrexia & 4 & || & - & - & - & - \\
\hline Gamma-glutamyltransferase increased & 3 & 8 & - & - & 1 & 3 \\
\hline Aspartate aminotransferase increased & 3 & 8 & । & 3 & - & - \\
\hline Dyspnoea & 3 & 8 & । & 3 & - & - \\
\hline Herpes zoster infection & 3 & 8 & । & 3 & - & - \\
\hline Hypoalbuminaemia & 3 & 8 & - & - & - & - \\
\hline Hypocalcaemia & 3 & 8 & 1 & 3 & - & - \\
\hline Hyponatraemia & 3 & 8 & 2 & 5 & - & - \\
\hline
\end{tabular}


Table 3 Overall efficacy results

\begin{tabular}{|c|c|c|c|}
\hline $\begin{array}{l}\text { Best overall } \\
\text { response, } n(\%)\end{array}$ & $\begin{array}{l}\text { All patients } \\
(n=35)\end{array}$ & $\begin{array}{c}\mathrm{PFI}<6 \\
\text { months }\left(n=23^{\mathrm{a}}\right)\end{array}$ & $\begin{array}{c}\text { PFI 6-12 } \\
\text { months }(n=12)\end{array}$ \\
\hline Partial response & $8(23)$ & $2(9)$ & $6(50)$ \\
\hline Stable disease & $15(43)$ & $10(43)$ & $5(42)$ \\
\hline Disease control rate & $23(66)$ & $12(52)$ & $11(92)$ \\
\hline Progressive disease & $12(34)$ & $11(48)$ & ( (8) \\
\hline $\begin{array}{l}\text { Time-related } \\
\text { endpoints, months }\end{array}$ & $\begin{array}{l}\text { All patients } \\
\quad(n=37)\end{array}$ & $\begin{array}{c}\mathrm{PFI}<6 \\
\text { months }(n=25)\end{array}$ & $\begin{array}{c}\text { PFI 6-12 } \\
\text { months }(n=12)\end{array}$ \\
\hline \multicolumn{4}{|l|}{ PFS } \\
\hline Median & 5.0 & 3.8 & 7.8 \\
\hline $95 \% \mathrm{Cl}$ & $3.1-6.9$ & $2.1-5.5$ & $5.8-9.7$ \\
\hline \multicolumn{4}{|c|}{ PFS in patients with disease control } \\
\hline Median & 6.6 & 5.0 & 7.8 \\
\hline $95 \% \mathrm{Cl}$ & $4.4-8.7$ & $4.6-5.3$ & $5.8-9.7$ \\
\hline \multicolumn{4}{|l|}{ OS } \\
\hline Median & 17.0 & 14.3 & 20.1 \\
\hline $95 \% \mathrm{Cl}$ & $10.4-23.6$ & $8.0-20.6$ & 19.6-20.6 \\
\hline
\end{tabular}

Abbreviations: $\mathrm{Cl}=$ confidence interval; $\mathrm{OS}=$ overall survival; $\mathrm{PFI}=$ platinum-free interval; PFS = progression-free survival. ${ }^{\text {a T }}$ wo patients were withdrawn from study before their first radiological reassessment due to symptomatic deterioration.
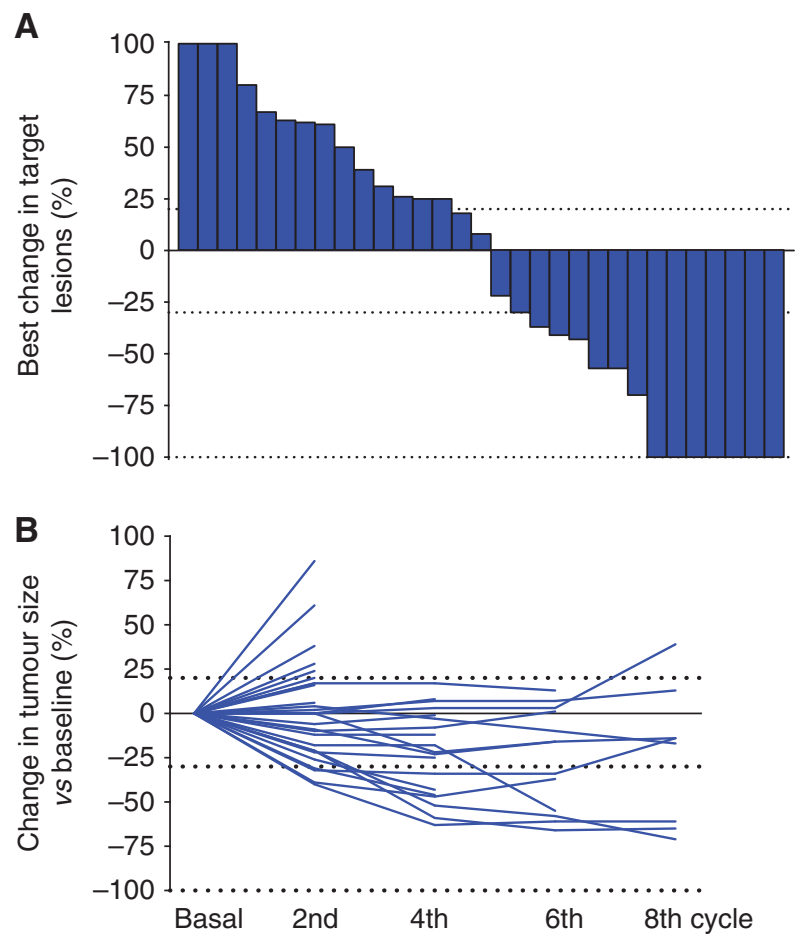

Total sum of

longest tumour

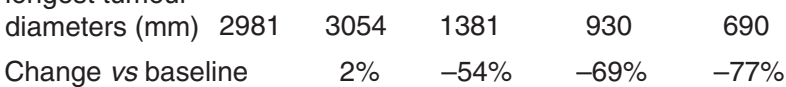

Figure I Individual patient radiological responses $(n=3 \mid)$. (A) Maximal change from baseline of target lesions. (B) Change from baseline over treatment of the total sum of longest diameters of target lesions. Tumour measurements were not repeated in six patients because of development of new lesions $(n=4)$ and clinical deterioration before reassessment $(n=2)$. Each bar or full line represent an individual patient. Upper, intermediate, and lower dotted lines indicate progression, partial, or complete response, respectively, according to the RECIST criteria.
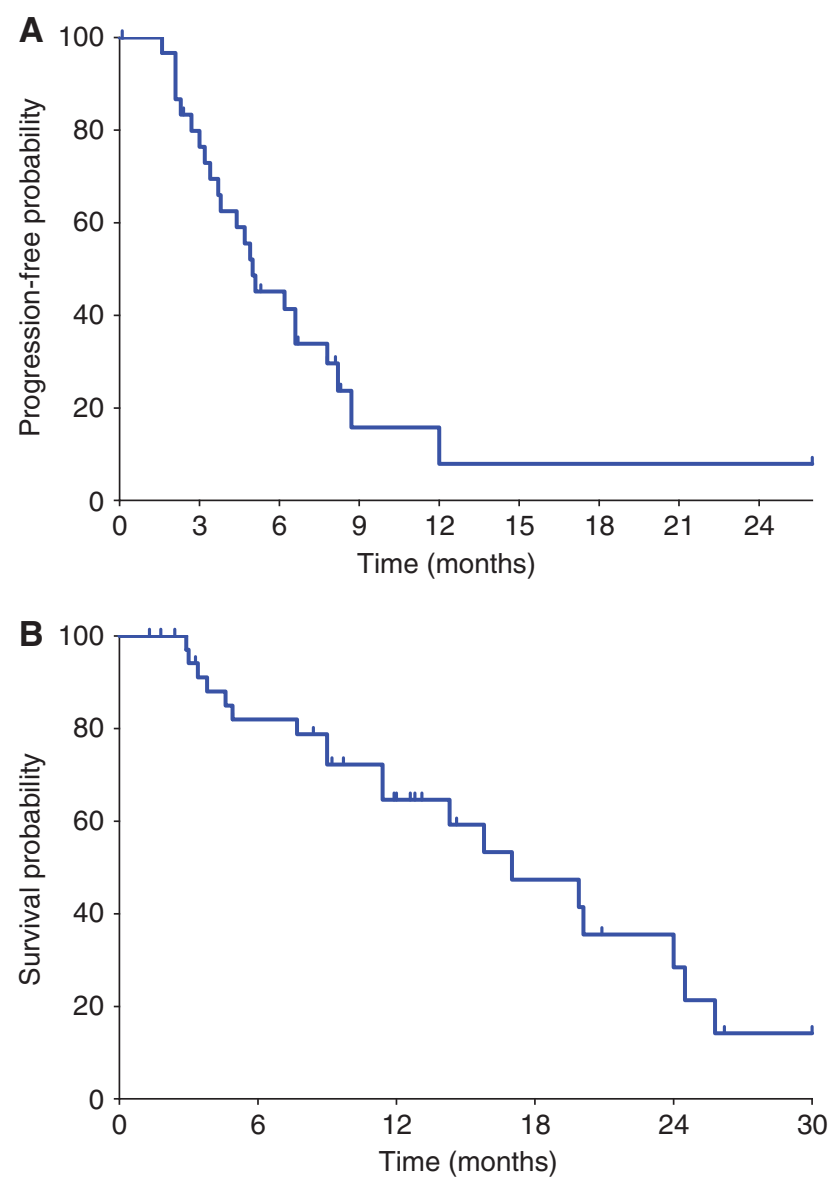

Figure 2 Kaplan-Meier estimates of $(\mathbf{A})$ progression-free survival and (B) overall survival for the whole study population $(n=37)$. Vertical ticks denote censored observations.

months in patients with disease control and 4.9 months in patients with early progressive disease $(P<0.0001)$.

By univariate Cox analyses, both longer PFI $(P=0.03)$ and higher baseline PBLC $(P=0.01)$ were significantly associated with better PFS, whereas improved OS was noted in patients with a PS of $0(P=0.002)$ and higher PBLC $(P=0.001)$.

Kaplan-Meier curves of PFS and OS for the whole study population according to baseline PBLC are depicted in Figure 3. In the subset with refractory/resistant relapse, patients with PBLC higher or lower than 1.2 per $\mathrm{ml}$ (i.e., the 25th percentile distribution value) had a median PFS of 4.9 and 2.6 months $(P=0.02)$, and median OS of 15.8 and 4.3 months $(P=0.0001)$, respectively. Consistently, similar results were noted when these subset analyses were repeated by testing the neutrophil-tolymphocyte ratio, with a cutoff value set at 4 (i.e., the 75 th percentile distribution value; data not shown).

\section{DISCUSSION}

This phase II trial demonstrated that the combination of NGRhTNF plus doxorubicin has interesting clinical activity and safe toxicity profile in relapsed ovarian cancer. A $23 \%$ response rate, with an overall disease control rate of $66 \%$ maintained for a median time of 6.6 months, a 5.0 months median PFS, and a 17.0 months median OS seem to be meaningful results, especially considering that two thirds of patients presented with platinumrefractory/resistant relapse. In particular, in this patient subset, 


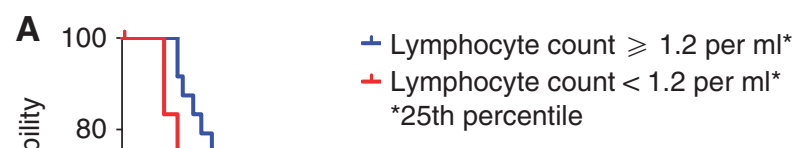

Log-rank $P=0.005$
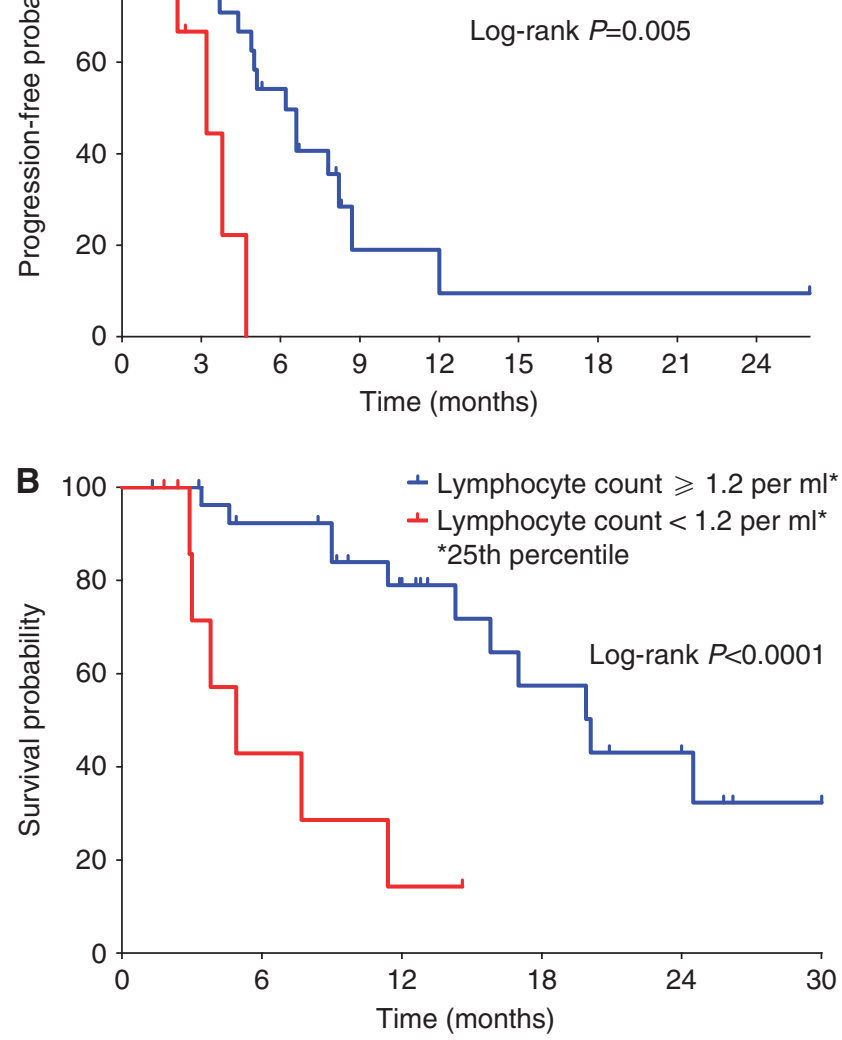

Figure 3 Kaplan-Meier estimates of $(\mathbf{A})$ progression-free survival and (B) overall survival for the whole study population $(n=37)$ according to the baseline peripheral blood lymphocyte count. Vertical ticks denote censored observations.

disease control rate was 52\%, median PFS was 3.8 months, and median OS was 14.3 months.

These results compare favourably with data recently reported by the Gynaecologic Oncology Group (GOG) in the same patient subset treated with single agents or combination regimens (Rose et al, 2010). In this retrospective GOG analysis, disease control rate was 39\%, median PFS was 2.4 months, and median OS was 10.2 months. Interestingly, the disease control rate correlated better with survival $(r=0.75 ; P=0.008)$ compared with response rate $(r=0.56 ; P=0.07)$.

Moreover, these results appear in line also with data from a recently published phase III trial (OVA-301 study; Monk et al, 2010; Poveda et al, 2011) in recurrent ovarian cancer patients receiving the combination of PLD plus trabectedin, in terms of response rate (28\%), median PFS (7.3 months), and median OS (22.4 months), considering that the proportion of patients with sensitive recurrences was higher in the OVA-301 trial (65\%) than in the present study (32\%).

\section{REFERENCES}

Bookman MA, Brady MF, McGuire WP, Harper PG, Alberts DS, Friedlander M, Colombo N, Fowler JM, Argenta PA, De Geest K, Mutch DG, Burger RA, Swart AM, Trimble EL, Accario-Winslow C, Roth LM (2009) Evaluation of new platinum-based treatment regimens in advanced-stage ovarian cancer: a phase III trial of the Gynecologic Cancer Intergroup. J Clin Oncol 27: 1419-1425
Interestingly, in the present study, a strong association was observed between baseline lymphocyte counts and outcomes, especially in the refractory/resistant subset. It is increasingly recognised that patients with refractory/resistant relapse represent a heterogeneous group. In fact, when these patients were grouped on the basis of the baseline lymphocyte count lower or higher than the first quartile, significant differences were found in the PFS (median, 2.6 vs 4.9 months) and OS (median, 4.3 vs 15.8 months). Therefore, a low baseline lymphocyte count is associated with an early progression and a short survival, whereas a high lymphocyte count correlates with prolonged clinical benefit even in refractory/ resistant disease. It is conceivable that patients with aggressive or chemotherapy-resistant disease may have an impaired antitumour immune response, as assessed by low lymphocyte counts. Accordingly, in the present study, the baseline lymphocyte counts tended to be lower in patients with refractory/resistant relapse than in patients with partially sensitive disease. These findings are consistent with a previously reported association between lack of intratumoural $\mathrm{T}$ lymphocytes and poor clinical outcome in advanced ovarian cancer (Zhang et al, 2003). Most importantly, these clinical observations are consistent with preclinical evidences of synergism between NGR-hTNF and doxorubicin shown in immunocompetent mice, being absent in nude mice lacking functional T cells (Sacchi et al, 2004), and with the rapid increase of tumour-infiltrated lymphocytes noted in NGR-hTNF-treated mice (Calcinotto et al, 2012). In this view, the lymphocyte count could be an easily accessible and reproducible blood-based biomarker that might be exploited for selecting patients with refractory/resistant disease, who would mostly benefit from the combination of NGR-hTNF and doxorubicin. Given the exploratory nature of the analysis, however, these findings are only hypothesis-generating and should be confirmed by a larger size and controlled trial.

The toxicity profiles of the two drugs did not apparently overlap. Most commonly reported AEs were those typically expected when each agent is given alone, consisting of grade 3-4 neutropaenia (62\% of patients) for doxorubicin and grade $1-2$ chills $(65 \%$ of patients) for NGR-hTNF. However, only one patient had febrile neutropaenia, whereas chills were short-lived and easily manageable. Notably, less than $10 \%$ of all recorded AEs were attributable to NGR-hTNF. Furthermore, the cardiovascular toxicities previously described for vascular targeting agents (van Heeckeren et al, 2006) did not appear in the present study, and most importantly, despite half of patients completing six or more cycles of doxorubicin, there was no exacerbation of the well-known cardiotoxicity profile of doxorubicin. These findings confirm the tolerability of the combination previously reported in phase I (Gregorc et al, 2009).

In conclusion, the evidence of a disease control achieved in more than half of patients and maintained for a median time of more than 6 months seem to be an interesting and remarkable result, especially in light of the manageable toxicity profile of the NGR-hTNF-doxorubicin combination. Given the outstanding use of PLD in ovarian cancer, and the preclinical synergism between low-dose TNF and liposomal formulation of doxorubicin (Ten Hagen et al, 2000), a randomised phase II trial (NCT01358071) testing PLD with or without NGR-hTNF in recurrent, platinumrefractory/resistant ovarian cancer is currently open to accrual.

Calcinotto A, Grioni M, Jachetti E, Curnis F, Mondino A, Parmiani G, Corti A, Bellone M (2012) Targeting TNF-a to neoangiogenic vessels enhances lymphocyte infiltration in tumors and increases the therapeutic potential of immunotherapy. $J$ Immunol 188: 2687-2694

Cannistra SA (2004) Cancer of the ovary. N Engl J Med 35: 2519-2529 
Carswell EA, Old LJ, Kassel RL, Green S, Fiore N, Williamson B (1975) An endotoxin-induced serum factor that causes necrosis of tumours. Proc Natl Acad Sci 72: 3666-3670

Curnis F, Sacchi A, Borgna L, Magni F, Gasparri A, Corti A (2000) Enhancement of tumour necrosis factor alpha antitumour immunotherapeutic properties by targeted delivery to aminopeptidase N (CD13). Nat Biotechnol 18: 1185-1190

Curnis F, Sacchi A, Corti A (2002) Improving chemotherapeutic drug penetration in tumours by vascular targeting and barrier alteration. J Clin Invest 110: 475-482

Dondossola E, Gasparri AM, Colombo B, Sacchi A, Curnis F, Corti A (2011) Chromogranin A restricts drug penetration and limits the ability of NGRTNF to enhance chemotherapeutic efficacy. Cancer Res 71: 5881-5890

Ferrandina G, Ludovisi M, Lorusso D, Pignata S, Breda E, Savarese A, Del Medico P, Scaltriti L, Katsaros D, Priolo D, Scambia G (2008) Phase III Trial of gemcitabine compared with pegylated liposomal doxorubicin in progressive or recurrent ovarian cancer. J Clin Oncol 26: 890-896

Gregorc V, Santoro A, Bennicelli E, Punt CJA, Citterio G, Timmer-Bonte JNH, Caligaris-Cappio F, Lambiase A, Bordignon C, van Herpen CML (2009) Phase Ib study of NGR-hTNF, a selective vascular targeting agent, administered at low doses in combination with doxorubicin to patients with advanced solid tumours. Br J Cancer 101: 219-224

Gregorc V, Citterio C, Vitali G, Spreafico A, Scifo P, Borri A, Donadoni G, Rossoni G, Corti C, Caligaris-Cappio F, Del Maschio A, Esposito A, De Cobelli F, Dell'Acqua F, Troysi A, Bruzzi P, Lambiase A, Bordignon C (2010a) Defining the optimal biological dose of NGR-hTNF, a selective vascular targeting agent, in advanced solid tumours. Eur J Cancer 46: 198-206

Gregorc V, Zucali PA, Santoro A, Ceresoli GL, Citterio G, De Pas TM, Zilembo N, De Vincenzo F, Simonelli M, Rossoni G, Spreafico A, Vigano MG, Fontana F, De Braud FG, Bajetta E, Caligaris-Cappio F, Bruzzi P, Lambiase A, Bordignon C (2010b) Phase II study of asparagine-glycinearginine-human tumor necrosis factor alpha, a selective vascular targeting agent, in previously treated patients with malignant pleural mesothelioma. J Clin Oncol 28: 2604-2611

Jemal A, Bray F, Center MM, Ferlay J, Ward E, Forman D (2011) Global cancer statistics. CA Cancer J Clin 61: 69-90

Kumaran GC, Jayson GC, Clamp AR (2009) Antiangiogenic drugs in ovarian cancer. Br J Cancer 100: 1-7

Lejeune FJ, Lienard D, Matter M, Ruegg C (2006) Efficiency of recombinant human TNF in human cancer therapy. Cancer Immun 6: 6-23

Monk BJ, Herzog TJ, Kaye SB, Krasner CN, Vermorken JB, Muggia FM, Pujade-Lauraine E, Lisyanskaya AS, Makhson AN, Rolski J, Gorbounova VA, Ghatage P, Bidzinski M, Shen K, Yuen-Sheung Ngan H, Vergote IB, Nam JN, Park YC, Lebedinsky CA, Poveda AM (2010) Trabectedin plus pegylated liposomal doxorubicin in recurrent ovarian cancer. J Clin Oncol 28: 3107-3114

Mutch DG, Orlando M, Goss T, Teneriello MG, Gordon AN, McMeekin SD, Wang Y, Scribner Jr DR, Marciniack M, Naumann RW, Secord AA (2007) Randomized phase III trial of gemcitabine compared to pegylated liposomal doxorubicin in patients with platinum-resistant ovarian cancer. J Clin Oncol 25: 2811-2818

Nakasone ES, Askautrud HA, Kees T, Park JH, Plaks V, Ewald AJ, Fein M, Rasch MG, Tan YX, Qiu J, Park J, Sinha P, Bissell MJ, Frengen E, Werb Z, Egeblad M (2012) Imaging tumor-stroma interactions during chemotherapy reveals contributions of the microenvironment to resistance. Cancer Cell 21: 488-503
Poveda A, Vergote I, Tjulandin S, Kong B, Roy M, Chan S, Filipczyk-Cisarz E, Hagberg H, Kaye SB, Colombo N, Lebedinsky C, Parekh T, Gómez J, Park YC, Alfaro V, Monk BJ (2011) Trabectedin plus pegylated liposomal doxorubicin in relapsed ovarian cancer: outcomes in the partially platinum-sensitive (platinum-free interval 6-12 months) subpopulation of OVA-301 phase III randomized trial. Ann Oncol 22: 39-48

Rangel R, Sun Y, Guzman-Rojas L, Ozawa MG, Sun J, Giordano RJ, Van Pelt CS, Tinkey PT, Behringer RR, Sidman RL, Wadih Arap W, Pasqualini R (2007) Impaired angiogenesis in aminopeptidase N-null mice. Proc Natl Acad Sci USA 104: 4588-4593

Rose PG, Tian C, Bookman MA (2010) Assessment of tumour response as a surrogate endpoint of survival in recurrent/platinum-resistant ovarian carcinoma: A Gynecologic Oncology Group study. Gynec Oncol 117: 324-329

Rustin GJ. (2003) Use of CA-125 to assess response to new agents in ovarian cancer trials. J Clin Oncol 21: 187-193

Sacchi A, Gasparri A, Gallo-Stampino C, Toma S, Curnis F, Corti A (2006) Synergistic antitumour activity of cisplatin, paclitaxel, and gemcitabine with tumour vasculature-targeted tumour necrosis factor-alpha. Clin Cancer Res 12: 175-182

Sacchi A, Gasparri A, Curnis F, Bellone M, Corti C (2004) Crucial role for interferon-gamma in the synergism between tumour vasculaturetargeted tumour necrosis factor alpha (NGR-TNF) and doxorubicin. Cancer Res 64: 7150-7155

Santoro A, Pressiani T, Citterio G, Rossoni G, Donadoni G, Pozzi F, Rimassa L, Personeni N, Bozzarelli S, Rossoni G, Colombi S, De Braud FG, Caligaris-Cappio F, Lambiase A, Bordignon C (2010) Activity and safety of NGR-hTNF, a selective vascular-targeting agent, in previously treated patients with advanced hepatocellular carcinoma. $\mathrm{Br} \mathrm{J}$ Cancer 103: $837-844$

Scheurich P, Thoma B, Ucer U, Pfizenmaier K (1987) Immunoregulatory activity of recombinant human tumour necrosis factor (TNF)- $\alpha$ : Induction of TNF receptors on human $\mathrm{T}$ cells and TNF-mediated enhancement of T cell responses. J Immunol 138: 1786-1790

Ten Hagen TML, Van der Veen AH, Nooijen PTGA, Van Tiel S, Seynhaeve ALB, Eggermont AMM (2000) Low-dose tumour necrosis factor- $\alpha$ augments antitumour activity of stealth liposomal doxorubicin in soft tissue sarcoma-bearing rats. Int J Cancer 87: 829-837

van Heeckeren WJ, Bhakta S, Ortis J (2006) Promise of new vasculardisrupting agents balanced with cardiac toxicity: is it time for oncologists to get to know their cardiologists? J Clin Oncol 24: 1485-1488

van Hensbergen Y, Broxtermann HJ, Rana S, van Diest PJ, Duyndam MCA, Hoekman K, Pinedo HM, Boven E (2004) Reduced growth, increased vascular area, and reduced response to cisplatin in CD13-overexpressing human ovarian cancer xenografts. Clin Cancer Res 10: 1180-1191

van Laarhoven HWM, Fiedler W, Desar IME, van Asten JJA, Sandrine Marreaud S, Lacombe D, Govaerts AS, Bogaerts J, Lasch P, TimmerBonte JNH, Lambiase A, Bordignon C, Punt CJA, Heerschap A, van Herpen CML (2010) Phase I clinical and magnetic resonance imaging study of the vascular agent NGR-hTNF in patients with advanced cancers (European Organization for Research and Treatment of Cancer Study 16041). Clin Cancer Res 16: 1315-1323

Zhang L, Conejo-Garcia JR, Katsaros D, Zhang L, Conejo-Garcia JR, Katsaros D, Gimotty PA, Massobrio M, Regnani G, Makrigiannakis A, Gray H, Schlienger K, Liebman MN, Rubin SC, Coukos G (2003) Intratumoural $\mathrm{T}$ cells, recurrence, and survival in epithelial ovarian cancer. N Engl J Med 348: 203-213

This work is published under the standard license to publish agreement. After 12 months the work will become freely available and the license terms will switch to a Creative Commons Attribution-NonCommercial-Share Alike 3.0 Unported License. 